Article

\title{
Decrease of Antimicrobial Resistance through Polyelectrolyte-Coated Nanoliposomes Loaded with $\beta$-Lactam Drug
}

\author{
Lina M. Arévalo ${ }^{1}$, Cristhian J. Yarce ${ }^{1}{ }^{\mathbb{C}}$, José Oñate-Garzón ${ }^{2} \mathbb{( 1 )}$ and Constain H. Salamanca ${ }^{1, *(\mathbb{C})}$ \\ 1 Maestría en Formulación de Productos Químicos y Derivados, Facultad de Ciencias Naturales, \\ Universidad Icesi, Calle 18 No. 122-135, Cali 760031, Colombia; linaarevaloh@hotmail.com (L.M.A.); \\ cjyarce@icesi.edu.co (C.J.Y.) \\ 2 Grupo de investigación en Química y Biotecnología (QUIBIO), Facultad de Ciencias Básicas, \\ Universidad Santiago de Cali, Cali 760031, Colombia; jose.onate00@usc.edu.co \\ * Correspondence: chsalamanca@icesi.edu.co; Tel.: +57-2-555-2334
}

Received: 22 November 2018; Accepted: 19 December 2018; Published: 23 December 2018

\begin{abstract}
Currently, one of the greatest health challenges worldwide is the resistance to antibiotic drugs, which has led to the pursuit of new alternatives for the recovery of biological activity, where the use of different types of nano-systems has shown an interesting potential. In this study, we evaluated the antibiotic activity of a model drug (ampicillin) encapsulated within coated-nanoliposomes on strains of Staphylococcus aureus with different antibiotic-resistance degrees. Hence, liposomes were elaborated by the ethanol injection method and were coated with a cationic polymer (Eudragit E-100) through the layer-by-layer process. Liposome characterization, such as size, polydispersity, zeta potential, and encapsulation efficiency were determined using dynamic light scattering and ultrafiltration/centrifugation techniques. Although biological activity was evaluated using three ATCC strains of S. aureus corresponding to ATCC 25923 (sensitive), ATCC 29213 (resistant) and ATCC 43300 (very resistant). The results showed changes in size (from $\sim 150$ to $220 \mathrm{~nm}$ ), polydispersity (from 0.20 to 0.45 ) and zeta potential (from -37 to $+45 \mathrm{mV}$ ) for the coating process. In contrast, encapsulation efficiency of approximately $70 \%$ and an increase in antibiotic activity of 4 and 18 times more on those S. aureus-resistant strains have been observed.
\end{abstract}

Keywords: coated liposomes; layer-by-layer; ampicillin; antimicrobial resistance

\section{Introduction}

Currently, antimicrobial resistance has been considered one of the greatest challenges in medicine according to the World Health Organization because this problem leads to the conventional therapy for many infectious diseases becoming difficult to treat [1]. According to the aforementioned paragraph, several types of research focused on (i) characterization of different molecular mechanisms involved in the generation of the drug resistance [2]; (ii) search for new molecules with antimicrobial potential [3]; and (iii) use of particle nanotechnology as a new tool to improve antibiotic performance, both new drugs and those that are practically obsolete [4,5]. Although there is a great diversity of microorganisms associated with this problem, Staphylococcus aureus has been highlighted to be one of the most relevant due to its high recurrence, making it one of the primary pathogens with resistance problems worldwide [6]. Such microorganism has generated several specific mechanisms of resistance, where the production of specialized enzymes ( $\beta$-lactamases) is one of the most used complexes because it has inactivated many conventional $\beta$-lactam antibiotic drugs [7]. In contrast, new tools of nanotechnology have allowed the development of new systems for the delivery of traditional 
antibiotics with drug-resistance issues, where nano-emulsions [8-10], polymer nanoparticles [11], lipid nanoparticles [12,13], dendrimers [14,15], and liposomes have been highlighted as the most used systems [4,16-18]. Liposomes have shown very interesting results due to their biocompatibility features, ease of processing, and versatility in modifying and conferring new properties $[19,20]$. In this regard, liposomes coated with polymers have been called in different ways, such as 'colloidosomes' or 'stealth liposomes' when ionic polymers or polymer derivative of polyethylene-glycol is used, respectively, which could be an interesting alternative in overcoming drug-resistance problems [1,21-23]. Moreover, this strategy of liposomes coated with polymers is useful in projecting pharmaceutical preparations for reconstitution, oral, and topical dosage forms. With the aim of contributing to finding solutions to this complex problem, we have been working in our laboratory regarding the use of nanoparticle technology as a potential strategy to help recover the biological activity of antibiotic drugs with resistance problems. Hence, several types of polymer-drug nanocomplexes have been evaluated on S. aureus strains with different resistance degrees $[11,24]$. However, in this work, we evaluated another alternative of nanoparticles corresponding to nano-liposomes that were modified superficially with a cationic polymer derived from Eudragit E-100.

\section{Materials and Methods}

\subsection{Materials}

Ampicillin (Fersinsa Gb) was supplied by Tecnoquímicas S.A. (Cali, Colombia), and was used as received. Soy lecithin or phosphatidylcholine Epikuron $200^{\mathrm{TM}}, \mathrm{Mw}=786 \mathrm{~g} / \mathrm{mol}$ from Cargill (Wayzata, MN, USA), dioleoyl-phosphatidyl-ethanolamine (DOPE, Mw $=744.03 \mathrm{~g} / \mathrm{mol}$ ) and cholesterol $(\mathrm{Mw}=386 \mathrm{~g} / \mathrm{mol}$ ) were purchased from Avanti Polar Lipids (Alabaster, AL, USA). Eudragit ${ }^{\circledR}$ E-100 from Evonik (Darmstadt, Germany) was used for liposomes surface coating. Ethanol USP grade was purchased from Sigma-Aldrich (St. Louis, MO, USA). (Merck) Ultrapure water was supplied from an Elix Essential Millipore ${ }^{\circledR}$ purification system, with a mean conductivity value of $\sim 1 \mu \mathrm{S} / \mathrm{cm}$.

\subsection{Preparation of Liposome Systems}

\subsubsection{Experimental Design Optimization}

A complete factorial design was performed to establish whether some process variables commonly used in the ethanol injection method [25], corresponding to (i) ionic strength, (ii) aging time, and (iii) membrane pore size, could significantly affect the physiochemical features of liposomes (dependent variables), such as particle size, polydispersity, and zeta potential. Statistical analysis was performed using the Minitab 17 software. The complete number of runs (treatments) that composed the experimental design is summarized in Table 1.

The liposomes were prepared on the basis of a sequential process defined in several steps. Step 1 (preparation of organic phase): Ethanolic solutions of lecithin, Epikuron $200^{\mathrm{TM}}(1.3 \mathrm{mg} / \mathrm{mL})$, cholesterol $(0.64 \mathrm{mg} / \mathrm{mL})$ and DOPE $(1.23 \mathrm{mg} / \mathrm{mL})$ were elaborated, from which volumes of $42.3,42.4$, and $15.3 \mu \mathrm{L}$ were taken, respectively, to obtain $100 \mu \mathrm{L}$ of the lipid mixture. Step 2 (phase mixture): $100 \mu \mathrm{L}$ of organic phase was slowly added to $100 \mu \mathrm{L}$ of different aqueous media (Ultra-pure water, PBS pH 7.4, $1 \mathrm{mM}$ and PBS pH 7.4, $10 \mathrm{mM}$ ), which were stirred (in vortex) for $1 \mathrm{~min}$ and left 'aging' at different times (5 and $20 \mathrm{~min}$ ). Step 3 (formation of liposomes): The resulting mixture between the organic phase and aqueous media was diluted in $300 \mu \mathrm{L}$ of the respective aqueous media. Step 4 (liposome purification): The diluted mixture was centrifuged (9000 g or $10000 \mathrm{rpm}$ ) in a micro-centrifuge (Hettich RCF 10538) for $6 \mathrm{~min}$, using ultrafiltration tubes (Eppendorf) with different pore sizes (MWCO $10 \mathrm{kDa}$ and MWCO $30 \mathrm{kDa}$ ). Subsequently, the fractions of purified liposomes were extracted and resuspended in $500 \mu \mathrm{L}$ of the respective aqueous media. Each assay was performed in triplicate. 
Table 1. Summary of the experimental design used.

\begin{tabular}{cccccccc}
\hline Run & $\begin{array}{c}\text { Ionic Strength } \\
(\mathbf{m M})\end{array}$ & $\begin{array}{c}\text { Cut-Off } \\
(\mathbf{M W C O})\end{array}$ & $\begin{array}{c}\text { Aging Time } \\
(\mathbf{m i n})\end{array}$ & Run & $\begin{array}{c}\text { Ionic Strength } \\
(\mathbf{m M})\end{array}$ & $\begin{array}{c}\text { Cut-Off } \\
\text { (MWCO) }\end{array}$ & $\begin{array}{c}\text { Aging Time } \\
\text { (min) }\end{array}$ \\
\hline 1 & 1 & $30 \mathrm{kDa}$ & 5 & 19 & 10 & $10 \mathrm{kDa}$ & 20 \\
2 & 0 & $30 \mathrm{kDa}$ & 20 & 20 & 10 & $30 \mathrm{kDa}$ & 5 \\
3 & 1 & $10 \mathrm{kDa}$ & 5 & 21 & 10 & $30 \mathrm{kDa}$ & 5 \\
4 & 1 & $30 \mathrm{kDa}$ & 20 & 22 & 0 & $10 \mathrm{kDa}$ & 20 \\
5 & 10 & $10 \mathrm{kDa}$ & 5 & 23 & 10 & $30 \mathrm{kDa}$ & 20 \\
6 & 1 & $10 \mathrm{kDa}$ & 20 & 24 & 10 & $10 \mathrm{kDa}$ & 20 \\
7 & 10 & $10 \mathrm{kDa}$ & 5 & 25 & 1 & $10 \mathrm{kDa}$ & 5 \\
8 & 10 & $10 \mathrm{kDa}$ & 5 & 26 & 1 & $30 \mathrm{kDa}$ & 20 \\
9 & 0 & $30 \mathrm{kDa}$ & 5 & 27 & 0 & $10 \mathrm{kDa}$ & 5 \\
10 & 1 & $30 \mathrm{kDa}$ & 20 & 28 & 1 & $10 \mathrm{kDa}$ & 20 \\
11 & 10 & $10 \mathrm{kDa}$ & 20 & 29 & 1 & $10 \mathrm{kDa}$ & 20 \\
12 & 0 & $30 \mathrm{kDa}$ & 5 & 30 & 0 & $10 \mathrm{kDa}$ & 5 \\
13 & 10 & $30 \mathrm{kDa}$ & 20 & 31 & 0 & $30 \mathrm{kDa}$ & 5 \\
14 & 1 & $30 \mathrm{kDa}$ & 5 & 32 & 10 & $30 \mathrm{kDa}$ & 20 \\
15 & 10 & $30 \mathrm{kDa}$ & 5 & 33 & 1 & $30 \mathrm{kDa}$ & 5 \\
16 & 1 & $10 \mathrm{kDa}$ & 5 & 34 & 0 & $10 \mathrm{kDa}$ & 20 \\
17 & 0 & $10 \mathrm{kDa}$ & 20 & 35 & 0 & $30 \mathrm{kDa}$ & 20 \\
18 & 0 & $10 \mathrm{kDa}$ & 5 & 36 & 0 & $30 \mathrm{kDa}$ & 20 \\
\hline
\end{tabular}

\subsubsection{Preparation of Liposomes Loaded with ampicillin}

In this case, the liposomes were prepared in a similar way as described in the previous section. However, some variations were made. In step 2, the addition of the organic phase (lipid mixture) was added to $100 \mu \mathrm{L}$ of ampicillin solution with a concentration of $6 \mathrm{mg} / \mathrm{mL}$, using PBS (pH 7.4, $10 \mathrm{mM}$ ) as media. The aging time was only $5 \mathrm{~min}$, and the pore size membrane used in step 4 was MWCO $30 \mathrm{kDa}$.

\subsubsection{Liposome Surface Modification}

First, the aqueous solutions of Eudragit ${ }^{\circledR}$ E-100 were prepared at different concentrations of $0.3 \%, 0.5 \%$, and $0.7 \%(\% w / v)$, fitting the media $\mathrm{pH}$ to 4.0 with $0.1 \mathrm{M} \mathrm{HCl}$. Subsequently, $1 \mathrm{~mL}$ of the respective polymeric solutions of Eudragit E-100 was added on $1 \mathrm{~mL}$ of liposomal dispersion loaded with ampicillin (previously prepared) at a rate of $50 \mu \mathrm{L} / \mathrm{min}$. Subsequently, the mixture was left under constant magnetic stirring at $300 \mathrm{rpm}$ for $8 \mathrm{~h}$ in a closed vessel. Finally, it was centrifuged at 10,000 rpm for $2 \mathrm{~min}$, using ultrafiltration tubes (Eppendorf) with $30 \mathrm{kDa}$ cut-off.

\subsection{Characterization of Liposome Systems}

\subsubsection{Zeta Potential and Size Measurements}

Particle size and zeta potential were determined using a Zetasizer nano ZSP (Malvern Instrument UK) with a red laser $(633 \mathrm{~nm}) \mathrm{He} / \mathrm{Ne}$. The particle size was measured using dynamic light scattering with an angle scattering of $173^{\circ}$ at $25^{\circ} \mathrm{C}$, using a quartz flow cell (ZEN0023), whereas the zeta potential was measured using a disposable folded capillary cell (DTS1070). The instrument reports the particle size as the mean particle diameter (z-average) and PDI ranging from 0 (monodisperse) to 1 (very broad distribution). All measurements were performed by triplicate, after an appropriate dilution (5:5000, $v / v$ ) of the liposome suspension in ultra-pure water and were reported as the mean and standard deviation of measurements made from freshly prepared liposomal dispersions.

\subsubsection{Encapsulation Efficiency}

In this case, the amount of ampicillin that was not retained in step 4 of the liposome preparation process (non-encapsulated ampicillin), which was contrasted against a calibration curve $\left(R^{2}=0.9995\right)$, 
was previously determined using UV spectroscopy at $256 \mathrm{~nm}$ and $25^{\circ} \mathrm{C}$ (Shimadzu, Kyoto, Japan). Therefore, the encapsulation efficiency was calculated, on the basis of Equation (1).

$$
E E=\frac{[\text { Drug }]_{\text {encapsulated }}}{[\text { Drug }]_{\text {non-encapsulated }}+[\text { Drug }]_{\text {encapsulated }}} \times 100,
$$

where the $[\text { Drug }]_{\text {total }}$ corresponds to the total amount of ampicillin before ultrafiltration step, whereas $[\text { Drug }]_{\text {encapsulated }}=[\text { Drug }]_{\text {total }}-[\text { Drug }]_{\text {non-encapsulated }}$.

\subsection{Stability of Liposomes}

The stability of the coated and non-coated liposomes was performed using a stability chamber at $40 \pm 1{ }^{\circ} \mathrm{C}$, where the change in liposomal size was evaluated for 7 days in triplicate.

\subsection{Antimicrobial Susceptibility Test}

Microbial susceptibility tests were performed based on the Clinical and Laboratory Standards Institute: CLSI Guidelines [26]. Bacteria were inoculated in Mueller Hinton broth and incubated overnight at $37^{\circ} \mathrm{C}$. Subsequently, the culture was diluted in Mueller Hinton broth until an $\mathrm{OD}_{625}$ of 0.1 was reached (approximately $1 \times 10^{8} \mathrm{CFU} / \mathrm{mL}$ ). The culture was diluted again by a factor 1:100. Subsequently, $50 \mu \mathrm{L}$ of culture was incubated for $18-20 \mathrm{~h}$ into 96 -well plates at $37^{\circ} \mathrm{C}$ with $50 \mu \mathrm{L}$ of antibiotic to reach a final inoculum of approximately $5 \times 10^{5} \mathrm{CFU} / \mathrm{mL}$. Ampicillin (Amp), ampicillin loaded in non-coated liposomes (NCL) and ampicillin loaded in coated liposomes (CL), were applied at 12 different serial concentrations from 0.09 to $201.7 \mu \mathrm{g} / \mathrm{mL}$. After incubation, the minimum inhibitory concentration (MIC) was determined by visual analysis.

\section{Results and Discussion}

\subsection{Optimization of Liposome Preparation Process}

The process variables (ionic strength of the aqueous media, membrane pore size, and aging time) have been found to significantly affect the response variables (size, polydispersity index [PDI], and zeta potential) and to interact with each other. Generally, the adjusted models presented a good correlation coefficient, which allows us to establish with confidence the best conditions for liposome elaboration. The results of the statistical analysis of the factorial model are shown in Figure 1.

Figure 1A shows that the aging time is the condition of the elaboration process that most affects the liposome size, where a change of $\sim 20 \mathrm{~nm}$ was observed. Other factors, such as membrane pore size and ionic strength of the aqueous media, seem not to significantly affect the liposomal size. This result is consistent because it has been found that liposomes of low phospholipid concentration (nM order), the process of vesicular stabilization depend on two relaxation periods of time. The lipid monomers moving easily from aggregates are formed in a short period, and the curvature of the lipid bilayer of the liposome is generated and stabilized over a slower period [27]. Therefore, it could be expected that agglomeration of the phospholipids will be greater at the interface for longer aging times; thus, vesicles will form with a larger size.

In contrast, the PDI always has low values $(<0.3)$ and was not affected significantly by either the aging time or ionic strength (Figure 1B). In the case of zeta potential, this parameter was found to be considerably affected by the process variables used in the liposome elaboration (Figure 1C). With regard to the ionic strength of the aqueous media, a change in the zeta potential value was observed from $\sim-47$ to $\sim-35 \mathrm{mV}$, which could be explained by the compression effect of the electrical double layer, given by the loss of the diffuse layer in the system [28,29]. Conversely, the decrease in the membrane pore size leads to a change in the zeta potential of $\sim-48$ to $\sim-36 \mathrm{mV}$. This change could be explained by rheological variations generated during the centrifugation/filtration process, where smaller pore causes greater shearing effects that may affect the electrical double layer through ion 
desorption from the liposomal surface. Finally, process conditions corresponding to ionic strength of $10 \mathrm{mM}$ for the PBS buffer $\mathrm{pH} 7.4$, membrane pore size of $30 \mathrm{kDa}$ and aging time of 5 min were selected because of such conditions, and the liposomes were obtained with adequate size ( $140 \mathrm{~nm})$, low polydispersity $(<0.3)$, and a high negative zeta potential value, which is necessary for the layer-by-layer coating process using the cationic polymer (Eudragit E-100).

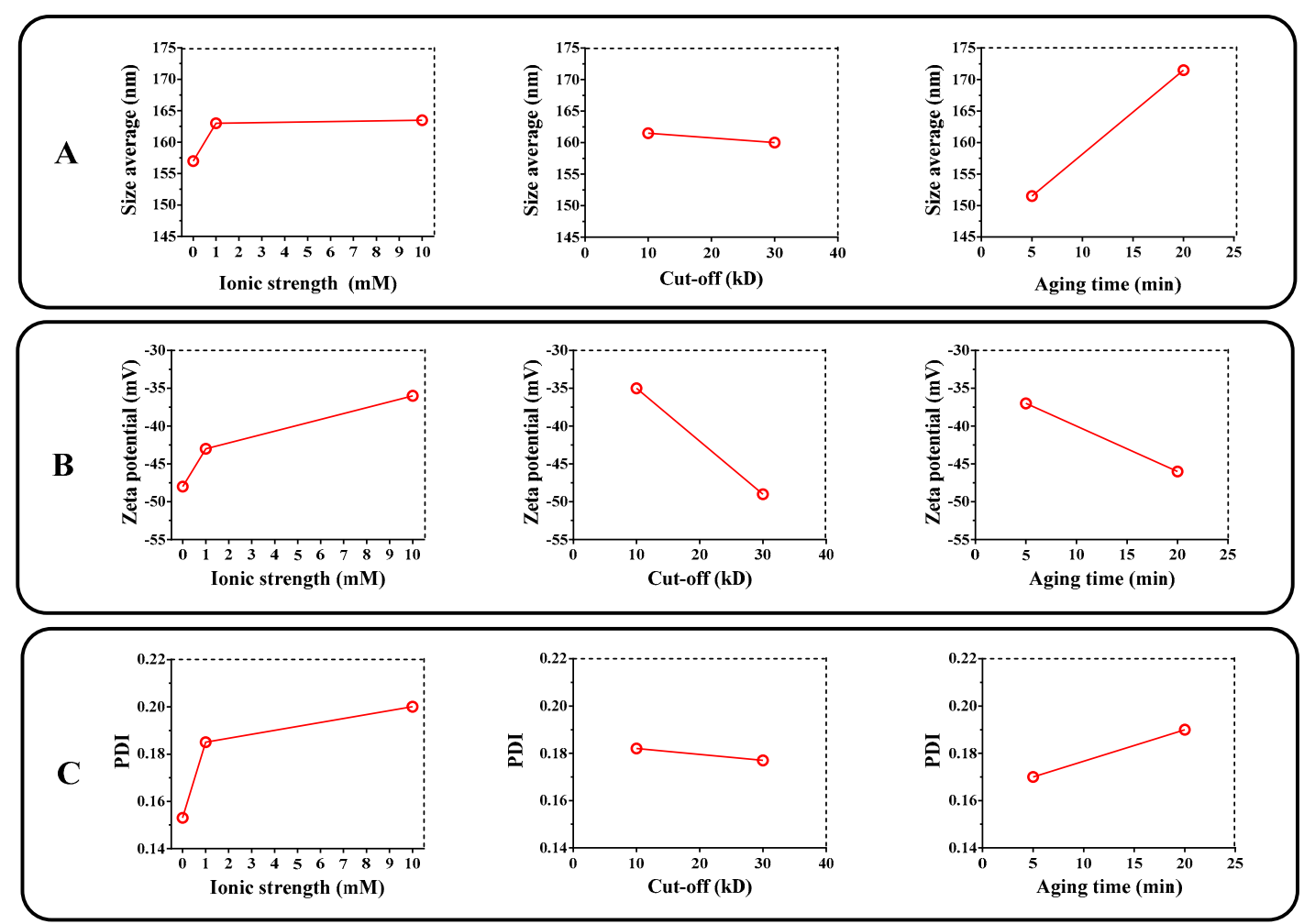

Figure 1. Effects plot of the process variables of liposome elaboration (ionic strength, membrane cut-off, and aging time) regarding the physicochemical features of liposomes. ((A) particle size, (B) zeta potential, (C) polydispersity index [PDI]).

\subsection{Liposome Surface Modification}

First, the change in particle size and zeta potential of the non-coated liposomes (without ampicillin) were determined against the $\mathrm{pH}$ (Figure 2A). Likewise, the effect of Eudragit E-100 polymeric concentration for zeta potential and viscosity was evaluated (Figure 2B) to establish the best conditions before loading the drug and modifying the liposomal surface. Secondly, the change in particle size, PDI, and zeta potential for liposomal systems loaded with ampicillin before and after the coating process was determined. The results are shown in Figure 3.

Figure 2A shows that the non-coated liposomes in aqueous solution change both the particle size and the zeta potential with respect to the media $\mathrm{pH}$. With regard to the liposomal size, the particle size tends to remain constant at $\sim 125 \mathrm{~nm}$ at $\mathrm{pH}$ values between 4.0 and 5.5, whereas an apparent transition occurs at $\mathrm{pH}>5.5$, wherein the liposomal size increases to $\sim 160 \mathrm{~nm}$ until $\mathrm{pH} 7.4$. The zeta potential increased with the increase in the media $\mathrm{pH}$, shifting from $\sim-18 \mathrm{mV}(\mathrm{pH} 4.0)$ to $\sim-40 \mathrm{mV}(\mathrm{pH} 7.4)$. These results are consistent, considering that at $\mathrm{pH}$ 7.4, the phosphatidylcholine has a fraction of carboxylate groups, which begin to neutralize with the decrease in $\mathrm{pH}$, affecting the electrical double layer in the liposomal surface $[30,31]$. Therefore, the loss of surface charge leads to a decrease in the electrostatic repulsion in lecithin heads, forming a more compact and smaller surface. In contrast, Figure 2B shows that the zeta potential of Eudragit E-100 polymer in acidulated aqueous solution ( $\mathrm{pH} \sim$ $4-5)$ is positive and indifferent of polymeric concentration $(\sim+50 \mathrm{mV})$. This result is consistent because this polymer derived from amino-alkyl methacrylate can be ionized in the acid medium, becoming a 
polyelectrolyte positively charged interface [32]. Conversely, the effect on the viscosity of the Eudragit E-100 polymeric solutions showed a marked increase above a concentration of $1.2 \% w / v$. Based on these results, the best conditions of polymeric concentration to perform the liposomal coating are between $0.1 \%$ and $0.7 \% w / v$. Therefore, the concentrations corresponding to $0.3,0.5$ and $0.7 \% w / v$ were selected for the liposome surface modification stage.

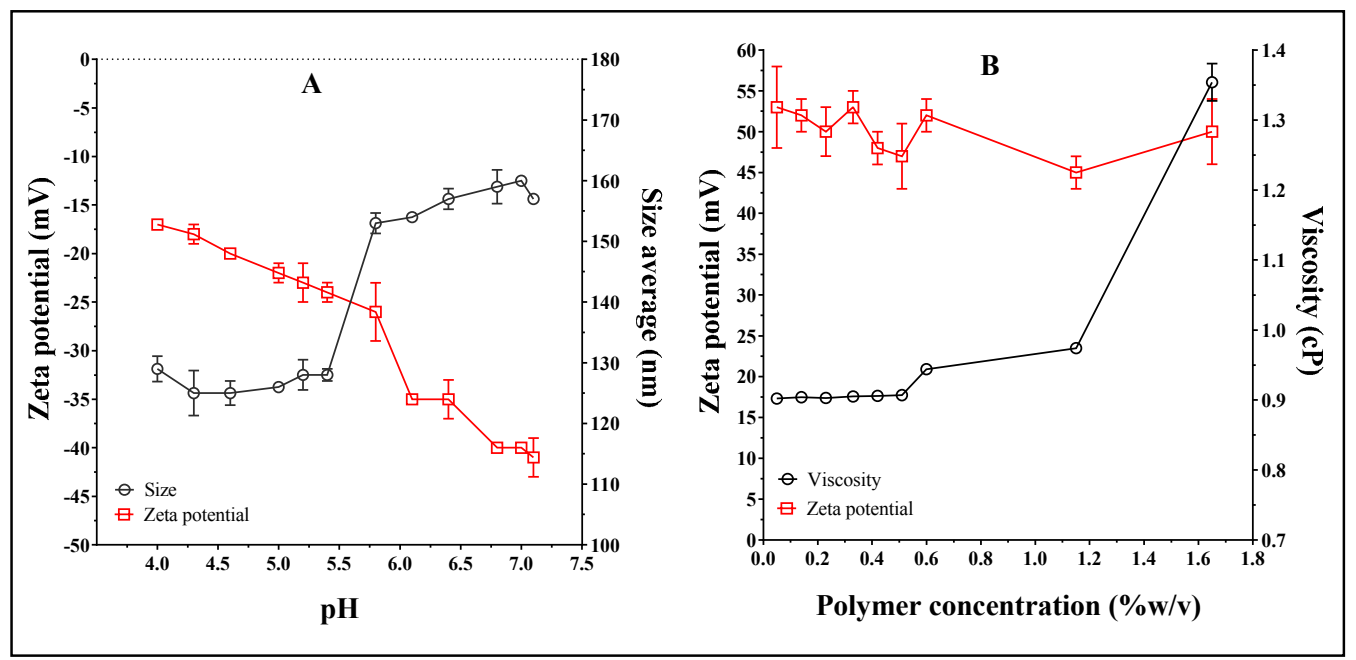

Figure 2. (A) Effect of media $\mathrm{pH}$ on the size and zeta potential of non-coated liposomes. (B) Effect of coating polymer (Eudragit E-100) concentration on zeta potential and viscosity in aqueous media.

Figure $3 \mathrm{~A}$ shows the change in the zeta potential of the liposomes concerning the coating process from $\sim-40 \mathrm{mV}$ (non-coated liposomes) to $\sim+50 \mathrm{mV}$ (coated liposomes). Such change is an indicator that surface modification occurred through the polymer deposition process layer-by-layer [33]. The change in the size of $\sim 150 \mathrm{~nm}$ (non-coated liposomes) to a size greater than $200 \mathrm{~nm}$ (coated liposomes) also suggested the occurrence of such surface modification (Figure 3B), where the increase in polymer concentration Eudragit E-100 led to a slight increase in liposomal size. With regard to PDI (Figure 3C), a change from 0.2 (non-coated liposomes) to values between 0.4 and 0.5 (coated liposomes) was observed, suggesting a modification in the size populations, which passed from a monodisperse $(\sim 150 \mathrm{~nm})$ to a polydisperse system $(\sim 200-250 \mathrm{~nm})$ with slightly different sizes. This result could be explained because of the random deposition of the cationic polymer on the liposomal surface, where different amounts of polymer chains are adhered with different types of conformations, obtaining coated liposomes with extended or coiled polymer chains, as shown in Figure 3E. Finally, the liposomal coating process did not significantly affect the encapsulation efficiency of ampicillin, which remained approximately $70 \%$ in both uncoated and coated liposomes (Figure 3D). 
A

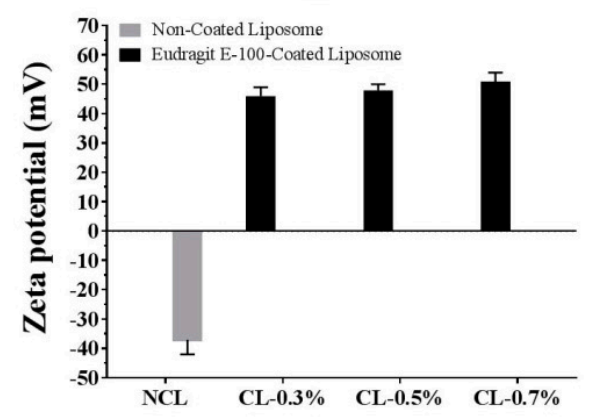

C

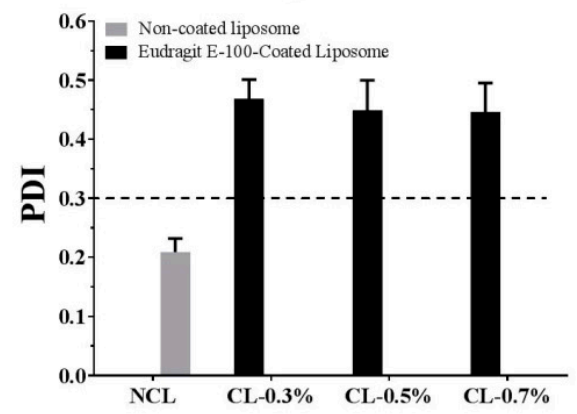

B

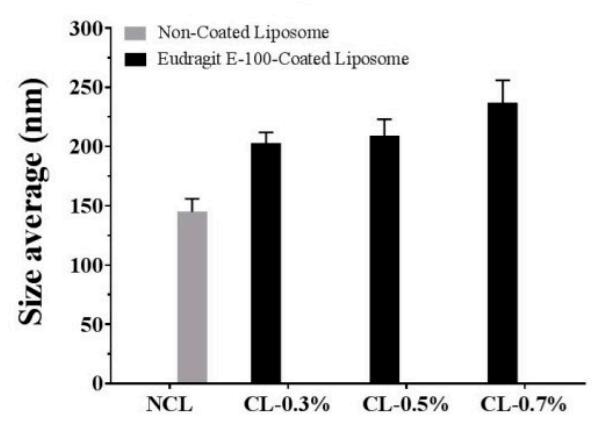

D

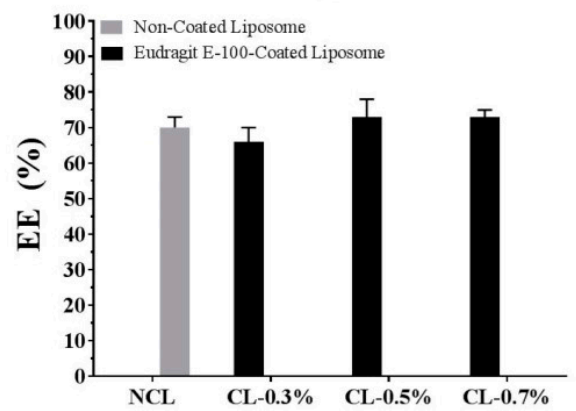

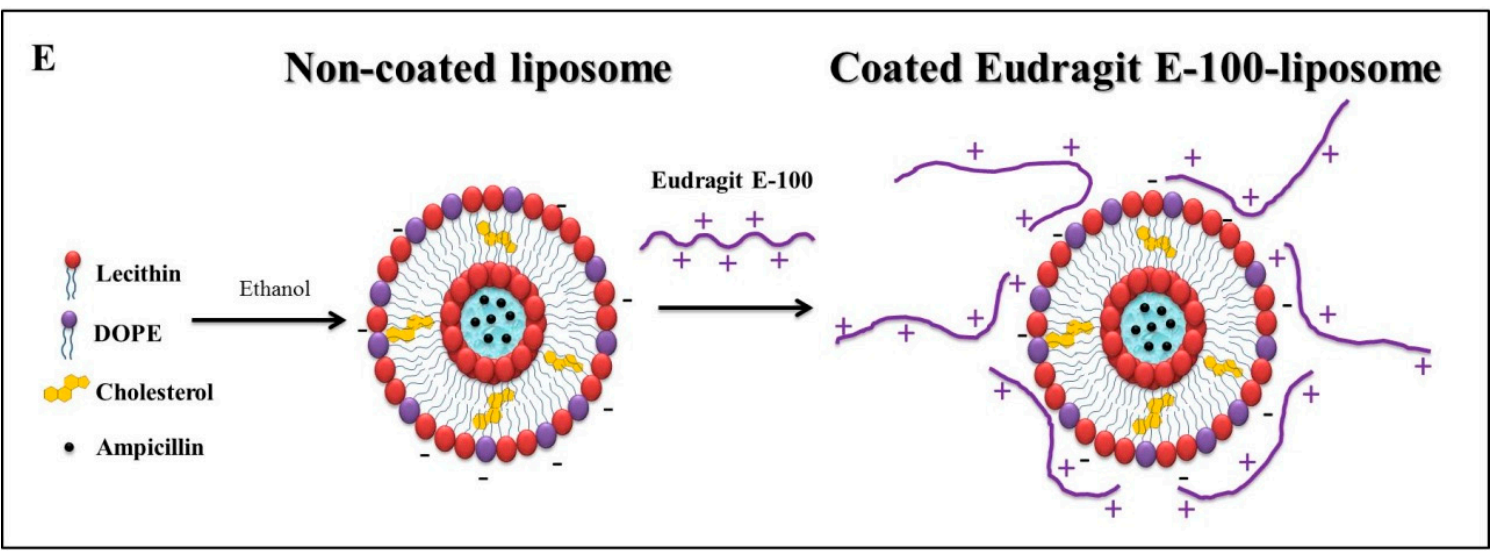

Figure 3. Change in (A) zeta potential, (B) particle size, (C) polydispersity index (PDI) and (D) encapsulation efficiency (EE) for liposomal systems loaded with ampicillin before and after the coating process. (E) Representative scheme of the liposomal coating process. NCL, non-coated liposome; CL, coated liposome.

\subsection{Stability of Liposome}

The results of the stability study showed that the liposomes coated with Eudragit E-100 polymer were more stable than the non-coated liposomes (Figure 4). This result could be explained considering the electrostatic stabilization effect [29], which increases with the adsorption of the polymer on the liposome surface. With regard to the amount of polymer used to coat the liposome, concentrations of $0.3 \% w / v$ and $0.5 \% w / v$ showed higher stability, whereas concentration of $0.7 \% w / v$ showed a marked increase in the liposomal size due to a competitive effect generated between polymeric adsorption on the liposome surface and aggregation between the same polymer chains. For this reason, liposomes coated with Eudragit E-100 at 0.5\% were chosen for biological evaluation. 


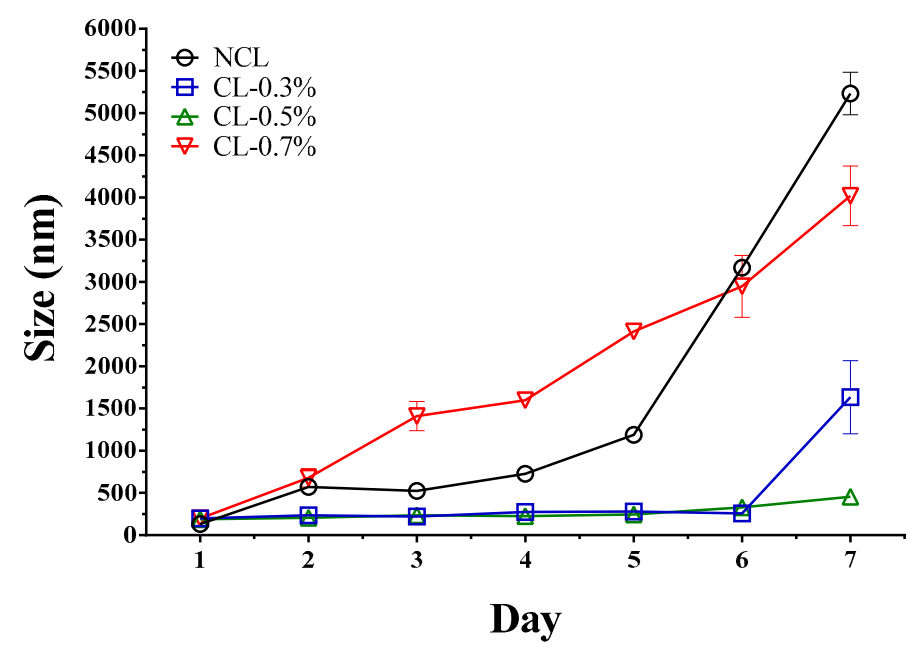

Figure 4. Evaluation of liposomal size change concerning time.

\subsection{Antimicrobial Susceptibility Test}

Figure 5 shows the minimum inhibitory concentrations (MIC) of ampicillin (Amp), ampicillin and Eudragit E-100 (coat polymer) (Amp-Eudragit E-100), ampicillin loaded in non-coated liposomes (Amp-NCL) and ampicillin loaded in coated liposomes (Amp-CL) on strains of S. aureus with different degrees of antimicrobial resistance. In addition, the MIC of the coating polymer (Eudragit-E-100) and the empty liposomes as negative test controls are included. In the case of non-encapsulated ampicillin, different MIC values were found corresponding to $0.19,6.3$, and $25.2 \mu \mathrm{g} / \mathrm{mL}$ for strains of $S$. aureus ATCC25923, ATCC29213, and ATCC43300, respectively. These values were consistent considering that the strain of S. aureus ATCC25923 is sensitive, whereas strains ATCC29213 and ATCC43300 have different degrees of antimicrobial resistance based on the Clinical and Laboratory Standards Institute: CLSI Guidelines [26].

In the case of the ATCC25923-sensitive strain, ampicillin could inhibit the synthesis of peptidoglycans in the bacterial cell wall due to the specific interaction with the penicillin-binding protein (PBP, specifically PBP1 and PBP3) affecting bacterial growth [34].

In contrast, the ATCC29213 strain showed a resistance effect against ampicillin because such strain is producing $\beta$-lactamase enzymes. Although the ATCC43300 strain showed the highest degree of resistance against ampicillin because of the production of $\beta$-lactamase enzymes, it also has a specific gene (mecA), which encodes an analogous PBP2a protein that has a lower affinity with the $\beta$-lactam drug, affecting its mechanism of pharmacological action [35,36].

Concerning Amp-NCL, the antimicrobial activity slightly increased in the three strains of S. aureus. This result may be explained considering that the liposomal systems can transport the antibiotic to the microorganism, preventing the degradation caused by $\beta$-lactamase enzymes, where the liposome adheres to the microorganism surface and is subsequently incorporated into the microorganism by an endocytosis mechanism [37].

In contrast, the ampicillin loaded in the liposomes coated with Eudragit E-100 (Amp-CL) displayed a marked increase in the antimicrobial activity, where the MIC was reduced from 0.19 to $0.09 \mu \mathrm{g} / \mathrm{mL}$ in the ATCC25923 strain, from 6.3 to $1.53 \mu \mathrm{g} / \mathrm{mL}$ in the ATCC29213 strain, and from 25.2 to $1.41 \mu \mathrm{g} / \mathrm{mL}$ in the ATCC43300 strain. The last result is very interesting because MIC $<2 \mu \mathrm{g} / \mathrm{mL}$ are classified as a penicillin-sensitive strain [26]. Therefore, the increase of 18 times in the antibacterial activity on S. aureus ATCC43300 strain is a significant and promising result because it shows that the use of nanotechnological systems can help recover drug activity with problems of antimicrobial resistance.

It is important to note that both the liposomes alone and the polymeric material Eudragit E-100 did not show marked antimicrobial activity, just at the maximum evaluated values $(512 \mu \mathrm{g} / \mathrm{mL})$. This result suggests that the materials used as ampicillin vehicles are innocuous. All these results show that nanoparticulate systems are in fact an alternative promissory in the treatment of infectious diseases 
with resistance problems because such nano-systems allow the recovery of antimicrobial activity with simple formulating strategies.

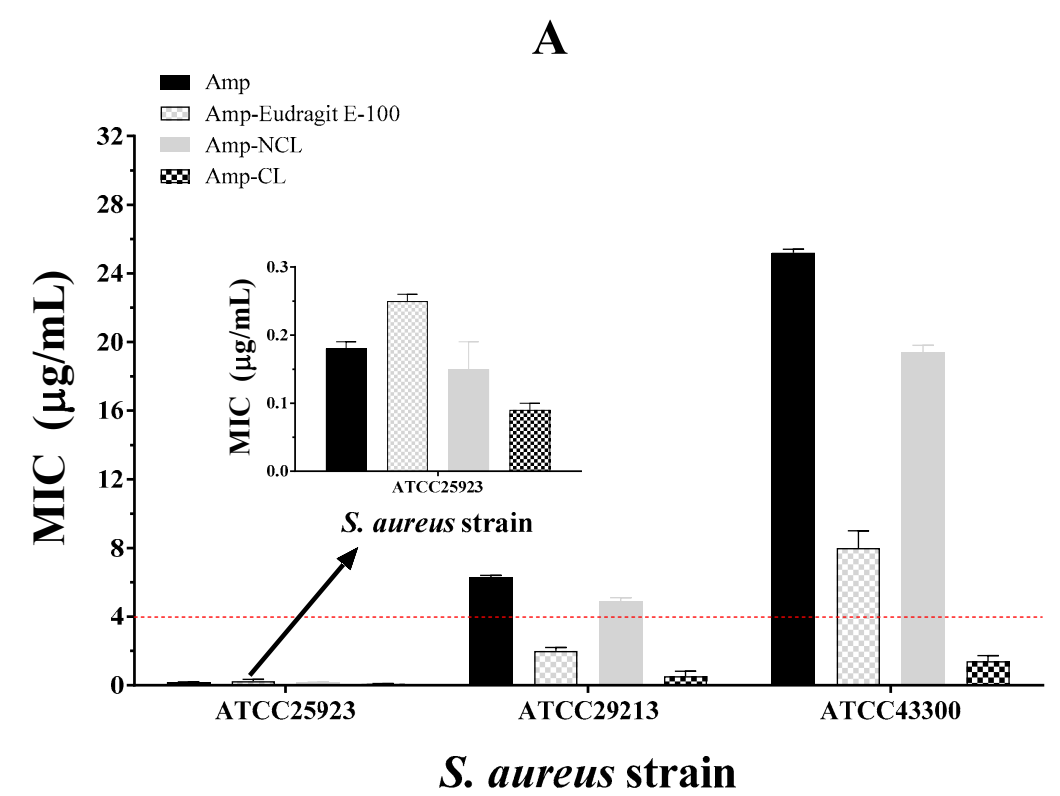

B

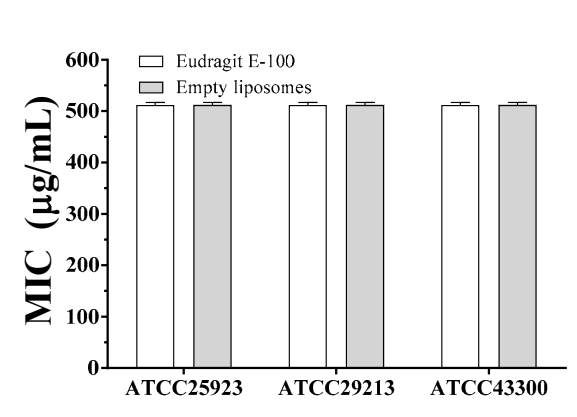

S. aureus strain
$\mathbf{C}$

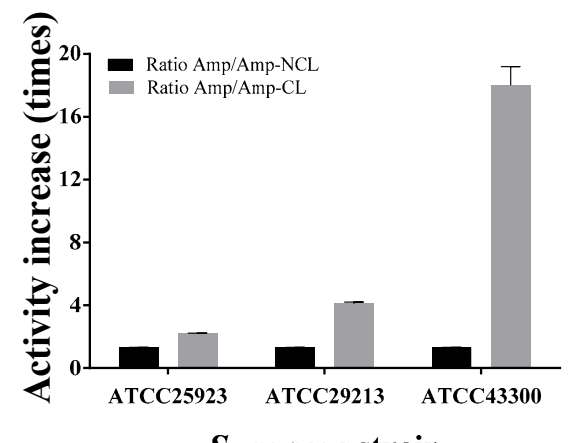

S. aureus strain

Figure 5. Minimum inhibitory concentration $(\mu \mathrm{g} / \mathrm{mL})$ of $(\mathbf{A})$ ampicillin (Amp), ampicillin and Eudragit E-100 mixture (Amp-Eudragit E-100), ampicillin loaded in non-coated liposomes (NCL) and ampicillin loaded in coated-liposomes (CL) and (B) empty liposomes and Eudragit E-100, against three strains of S. aureus with different antimicrobial resistance degrees. (C) Comparison of the increase in the antimicrobial activity of ampicillin loaded between non-coated and coated liposomes.

\section{Conclusions}

The preparation method used allowed us to obtain liposomes with nanometric sizes of approximately $150 \mathrm{~nm}$, which began to aggregate from the first day of preparation. In contrast, the polymeric coating with Eudragit E-100 led to an increase of approximately $50 \mathrm{~nm}$ in size and to an inversion of the liposomal zeta potential, passing from a negative to a positive surface. Likewise, such surface modification in the liposomes showed an improvement in the stability, being better at polymer coating concentrations of $0.3 \% w / v$ and $0.5 \% w / v$. The polymeric coating did not also affect the encapsulation efficiency of ampicillin, which was approximately $70 \%$. With regard to the antibacterial effect, a marked increase was seen with the liposomal coating, particularly in resistant $S$. aureus strains, which is a very important and promising result that shows that the use of nanoparticle systems can be an interesting alternative to combat the current problems of antimicrobial resistance. 
Author Contributions: L.M.A. and C.J.Y. performed the liposome elaboration and characterization. J.O.-G. carried out the antimicrobial susceptibility tests. C.H.S. designed the experiments, analyzed the data, and wrote the manuscript. All authors discussed and commented on the manuscript.

Funding: This research received no external funding.

Acknowledgments: The authors thank Icesi University for the grants: CA041368 and CA041369, and University of Santiago de Cali. J.O.-G. thanks Colciencias-Colombia for providing the Post-Doctoral Fellowship.

Conflicts of Interest: The authors declare no competing interests.

Data Availability: The datasets generated and analyzed during the current study are available from the corresponding author on reasonable request.

\section{References}

1. Brooks, B.D.; Brooks, A.E. Therapeutic strategies to combat antibiotic resistance. Adv. Drug Deliv. Rev. 2014, 78, 14-27. [CrossRef] [PubMed]

2. Davies, J.; Davies, D. Origins and evolution of antibiotic resistance. Microbiol. Mol. Biol. Rev. 2010, 74, 417-433. [CrossRef] [PubMed]

3. Tacconelli, E.; Carrara, E.; Savoldi, A.; Harbarth, S.; Mendelson, M.; Monnet, D.L.; Pulcini, C. Discovery, research, and development of new antibiotics: The WHO priority list of antibiotic-resistant bacteria and tuberculosis. Lancet Infect. Dis. 2017, 3099, 1-10. [CrossRef]

4. Pinto-Alphandary, H.; Andremont, A.; Couvreur, P. Targeted delivery of antibiotics using liposomes and nanoparticles: Research and applications. Int. J. Antimicrob. Agents 2000, 13, 155-168. [CrossRef]

5. Kalhapure, R.S.; Suleman, N.; Mocktar, C.; Seedat, N.; Govender, T. Nanoengineered drug delivery systems for enhancing antibiotic therapy. J. Pharm. Sci. 2015, 104, 872-905. [CrossRef] [PubMed]

6. De Araujo, F.P.; Cruciani, M. Worldwide Epidemiology and Antibiotic Resistance of Staphylococcus aureus. In Staphylococcus Aureus; Fabio, B., Rino, R., Guido, G., Eds.; Springer: New York, NY, USA, 2016; pp. 21-56.

7. Yılmaz, E.Ş.; Aslantaş, Ö. Antimicrobial resistance and underlying mechanisms in Staphylococcus aureus isolates. Asian Pac. J. Trop. Med. 2017, 10, 1059-1064. [CrossRef] [PubMed]

8. Hamouda, T.; Myc, A.; Donovan, B.; Shih, A.Y.; Reuter, J.D.; Baker, J.R. A novel surfactant nanoemulsion with a unique non-irritant topical antimicrobial activity against bacteria, enveloped viruses and fungi. Microbiol. Res. 2001, 156, 1-7. [CrossRef] [PubMed]

9. LiPuma, J.J.; Rathinavelu, S.; Foster, B.K.; Keoleian, J.C.; Makidon, P.E.; Kalikin, L.M.; Baker, J.R. In vitro activities of a novel nanoemulsion against Burkholderia and other multidrug-resistant cystic fibrosis-associated bacterial species. Antimicrob. Agents Chemother. 2009, 53, 249-255. [CrossRef] [PubMed]

10. Hwang, Y.Y.; Ramalingam, K.; Bienek, D.R.; Lee, V.; You, T.; Alvarez, R. Antimicrobial activity of nanoemulsion in combination with cetylpyridinium chloride in multidrug-resistant acinetobacter baumannii. Antimicrob. Agents Chemother. 2013, 57, 3568-3575. [CrossRef] [PubMed]

11. Salamanca, C.H.; Yarce, C.J.; Roman, Y.; Davalos, A.F.; Rivera, G.R. Application of Nanoparticle Technology to Reduce the Anti-Microbial Resistance through $\beta$-Lactam Antibiotic-Polymer Inclusion Nano-Complex. Pharmaceuticals 2018, 11, 19. [CrossRef] [PubMed]

12. Cortesi, R.; Valacchi, G.; Muresan, X.M.; Drechsler, M.; Contado, C.; Esposito, E.; Grandini, A.; Guerrini, A.; Forlani, G.; Sacchetti, G. Nanostructured lipid carriers (NLC) for the delivery of natural molecules with antimicrobial activity: Production, characterisation and in vitro studies. J. Microencapsul. 2017, 34, 63-72. [CrossRef] [PubMed]

13. Pignatello, R.; Leonardi, A.; Fuochi, V.; Petronio, G.P.; Greco, A.S.; Furneri, P.M. A method for efficient loading of ciprofloxacin hydrochloride in cationic solid lipid nanoparticles: Formulation and microbiological evaluation. Nanomaterials 2018, 8, 304. [CrossRef] [PubMed]

14. Calabretta, M.K.; Kumar, A.; McDermott, A.M.; Cai, C. Antibacterial activities of poly(amidoamine) dendrimers terminated with amino and poly(ethylene glycol) groups. Biomacromolecules 2007, 8, 1807-1811. [CrossRef] [PubMed]

15. Scorciapino, M.A.; Serra, I.; Manzo, G.; Rinaldi, A.C. Antimicrobial Dendrimeric Peptides: Structure, Activity and New Therapeutic Applications. Int. J. Mol. Sci. 2017, 18, 542. [CrossRef] [PubMed]

16. Çă̆daş, M.; Sezer, A.D.; Bucak, S. Liposomes as Potential Drug Carrier Systems for Drug Delivery. In Application of Nanotechnology in Drug Delivery; InTech: Vienna, Austria, 2014. 
17. Maherani, B.; Arab-Tehrany, E.; Mozafari, M.R.; Gaiani, C.; Linder, M. Liposomes: A Review of Manufacturing Techniques and Targeting Strategies. Curr. Nanosci. 2011, 7, 436-452. [CrossRef]

18. Eloy, J.O.; Claro de Souza, M.; Petrilli, R.; Barcellos, J.P.A.; Lee, R.J.; Marchetti, J.M. Liposomes as carriers of hydrophilic small molecule drugs: Strategies to enhance encapsulation and delivery. Colloids Surfaces B Biointerfaces 2014, 123, 345-363. [CrossRef] [PubMed]

19. Jain, A.; Jain, S.K. In vitro release kinetics model fitting of liposomes: An insight. Chem. Phys. Lipids 2016, 201, 28-40. [CrossRef]

20. Drulis-Kawa, Z.; Dorotkiewicz-Jach, A. Liposomes as delivery systems for antibiotics. Int. J. Pharm. 2010, 387, 187-198. [CrossRef]

21. Marianecci, C.; Petralito, S.; Rinaldi, F.; Hanieh, P.N.; Carafa, M. Some recent advances on liposomal and niosomal vesicular carriers. J. Drug Deliv. Sci. Technol. 2016, 32, 256-269. [CrossRef]

22. Bangale, G.S.; Rajesh, K.S.; Shinde, G. V Stealth Liposomes: A Novel Approach of Targeted Drug Delivery in Cancer Therapy. Int. J. Pharma Sci. Res. 2014, 5, 750-759.

23. Nag, O.K.; Awasthi, V. Surface engineering of liposomes for stealth behavior. Pharmaceutics 2013, 5, 542-569. [CrossRef] [PubMed]

24. Arenas Fernández, T.; Mora Arango, C.L.; Salamanca, C.H.; Jaramillo Flórez, M.C. Actividad del (2E)-3-(2, 3-dimetoxifenil)-1-(4-metilfenil) prop-2-en-1-ona en presencia del poli(ácido maleico-co-2-vinil-pirrolidona) sobre un aislamiento clínico de Staphylococcus aureus productor de $\beta$-lactamasas TT-Activity of (2E)-3-(2, 3-dimetoxif. Iatreia 2012, 25, 12-19.

25. Ukawa, M.; Akita, H.; Hayashi, Y.; Ishiba, R.; Tange, K.; Arai, M.; Kubo, K.; Higuchi, Y.; Shimizu, K.; Konishi, S.; et al. Neutralized nanoparticle composed of SS-cleavable and $\mathrm{pH}$-activated lipid-like material as a long-lasting and liver-specific gene delivery system. Adv. Healthc. Mater. 2014, 3, 1222-1229. [CrossRef] [PubMed]

26. CLSI. Performance Standards for Antimicrobial Susceptibility Testing; Twenty-Fifth Informational Supplement; CLSI: Wayne, PA, USA, 2015; ISBN 1562387855.

27. Aniansson, E.A.G.; Wall, S.N.; Almgren, M.; Hoffman, H.; Kielman, I.; Ulbricht, W.; Zana, R.; Lang, J.; Tondre, C. Theory of the kinetics of micellar equilibria and quantitative interpretation of chemical relaxation studies of micelar solutions of ionic surfactants. J. Phys. Chem. 1976, 80, 905-922. [CrossRef]

28. Carrión, F.J.; De la Maza, A.; Parra, J.L. La influencia de la fuerza iónica y la carga de la bicapa lipídica en la estabilidad de liposomas. J. Colloid Interface Sci. 1994, 164, 78-87. [CrossRef]

29. Sabín, J.; Prieto, G.; Ruso, J.M.; Hidalgo-Álvarez, R.; Sarmiento, F. Size and stability of liposomes: A possible role of hydration and osmotic forces. Eur. Phys. J. E 2006, 20, 401-408. [CrossRef] [PubMed]

30. Yandrapati, R.K. Effect of Lipid Composition on the Physical Properties of Liposomes: A Light Scattering Study; Missouri University of Science and Technology: Rolla, MO, USA, 2012.

31. Kotyńska, J.; Figaszewski, Z.A. Adsorption equilibria between liposome membrane formed of phosphatidylcholine and aqueous sodium chloride solution as a function of $\mathrm{pH}$. Biochim. Biophys. Acta Biomembr. 2005, 1720, 22-27. [CrossRef]

32. Alasino, R.V.; Leonhard, V.; Bianco, I.D.; Beltramo, D.M. Eudragit E100 surface activity and lipid interactions. Colloids Surfaces B Biointerfaces 2012, 91, 84-89. [CrossRef]

33. Hasanovic, A.; Hollick, C.; Fischinger, K.; Valenta, C. Improvement in physicochemical parameters of DPPC liposomes and increase in skin permeation of aciclovir and minoxidil by the addition of cationic polymers. Eur. J. Pharm. Biopharm. 2010, 75, 148-153. [CrossRef]

34. Grema, H.A. Methicillin Resistant Staphylococcus aureus (MRSA): A Review. Adv. Anim. Vet. Sci. 2015, 3, 79-98. [CrossRef]

35. Stapleton, P.D.; Taylor, P.W. Methicillin resistance in Staphylococcus aureus: Mechanisms and modulation. Sci. Prog. 2002, 85, 57-72. [CrossRef] [PubMed]

36. Stapleton, P.D.; Taylor, P.W. Methicillin reistance in staphylococcus aureus. Lancet 1970, 295, 800-804.

37. Daraee, H.; Etemadi, A.; Kouhi, M.; Alimirzalu, S.; Akbarzadeh, A. Application of liposomes in medicine and drug delivery. Artif. Cells Nanomed. Biotechnol. 2016, 44, 381-391. [CrossRef] [PubMed]

(C) 2018 by the authors. Licensee MDPI, Basel, Switzerland. This article is an open access article distributed under the terms and conditions of the Creative Commons Attribution (CC BY) license (http:/ / creativecommons.org/licenses/by/4.0/). 